\title{
Cancer Care Challenges in COVID-19 Pandemic: A Prospective from Tertiary Cancer Centre in Eastern India
}

\author{
Anup Kumar, Rashmi Singh, Rajanigandha Tudu, Praveer Munda
}

Department of Radiation Oncology, RIMS, Ranchi, India.

Asian Pac J Cancer Care, 5 (Suppl 1), 121-122

\section{Introduction}

The whole world is witnessing the Corona virus disease-2019 (COVID-19) pandemic. India is having presently 5,08,953 cases of COVID -19 and 15,685 patients deaths as on $25^{\text {th }}$ June 2020 and the total number of cases in Jharkhand, a state in the eastern zone of the country is 2,207 with 11 deaths [1].

Since the detection of $1^{\text {st }}$ case on $29^{\text {th }}$ January 2020 in India, there was nationwide fear, as we were observing the fatalities per day in other countries like China, Italy, the US, etc [2]. Subsequently, In India complete lockdown was announced from $25^{\text {th }}$ March 2020. There was high fear among hospital personnel being at the risk of catching an infection while taking care of the patients, and there have been reports of infection and deaths of many health care workers while delivering their duties [3]. In Jharkhand, our tertiary care facility also followed the health advisory and suspended outdoor facilities, cancelled routine surgeries, and started teleconsultation to decrease the overcrowding of patients and attendants in the hospital to decrease the risk to one and all, however, emergency services were available for all. With this step, patients' footfall to hospital decreased but simultaneously in the oncology setting it was quite challenging as this would upstage the disease in many patients. So, prioritizing strategies were made to combat this challenge to have the best possible management of cancer patients. Also, there are reports of high fatality in patients having cancer and other co-morbid conditions like diabetes mellitus, hypertension, chronic kidney disease [4].

Our hospital has a dedicated separate block for COVID patients' diagnosis and management. All patients coming for oncology consultation were sent for COVID-19 screening in the hospital. A thermal screening of all patients was done before allowing their entry to Oncology building.

Real-time polymerase chain reaction (RT-PCR) testing for COVID-19 was done in cancer patients as per
Submission Date: 07/08/2020 Acceptance Date: 08/08/2020

the national Indian council of medical research (ICMR) guidelines based on their symptoms, history of travel, and/ or history of contact with COVID-19 positive patients [5]. The routine practice of social distancing, wearing a mask, face shield, and practicing hand hygiene by all hospital staff and patients were strictly followed. Regular sanitization of the workplace was carried out regularly. Hospital staff wore personal protective equipment (PPE) judicially as per the institutional standard protocol. Till now none of our cancer patients were found to be COVID-19 positive.

After screening patients were evaluated in the oncology department for the needful. New patients underwent diagnostic workup and old patients were planned for awaited treatment. As the oncosurgery department was still not operable for routine planned surgeries at our hospital as per the health advisory, patients were referred for neoadjuvant chemotherapy (NACT)/ chemo-radiotherapy $(\mathrm{CT}+\mathrm{RT})$ as per the case details to slow down the disease progression and to buy some time for surgery. Also, many of our head and neck cancer and other patients come with an advanced presentation, so, in that case, NACT/CT+RT would be the most suitable treatment. For chemotherapy, there was a mandatory prescription of Filgrastim/ peg-Filgrastim post-chemotherapy schedules to decrease the risk of neutropenia and subsequent complications in this COVID -19 time. Also, general advice for the intake of a well-cooked nutritious diet, lukewarm saline gargles, and maintaining good personal care was given. Patients who were on an oral form of treatment as hormone or immune-chemotherapy, they were prescribed for 2-3 months duration at once and asked for blood monitoring at local labs. This further reduces the patient volume in the oncology setting.

Cancer patients requiring radiotherapy were assessed for the aim of treatment. Any cancer patient with low-risk

\footnotetext{
Corresponding Author:

Dr. Rashmi Singh

Department of Radiation Oncology, RIMS, Ranchi, India.

Email: rashmisingh.noor1@gmail.com
} 
features, for them radiotherapy can also be delayed for 3-4 weeks [6]. In general radiotherapy in adjuvant and radical setting goes on for 5-7 weeks depending on the site of cancer. In the current pandemic time, all radiation oncologists are working out to decrease this duration to a shorter period by carefully assessing the target coverage and organ at risk toxicity. So, we are changing to hypo-fractionation schedules from the 1.8-2Gy/\# conventional protocols where feasible to decrease the patient stay in and around the hospital and thus reducing the risk of COVID-19 infection to all involved personnel in the care of patients. We all know the non-inferiority results of hypo-fractionation schedules in breast and prostate cancer in curative settings and these are widely practiced as a standard of care. There are recent recommendations made by ASTRO-ESTRO for head and neck cancer radiotherapy of hypo-fractionation schedules to ease this pandemic situation [6]. We are also practicing $55 \mathrm{~Gy} / 20 \#-60 \mathrm{~Gy} / 24 \#$, 5\# per week in head and neck cancer radiotherapy, and this prescription dose are decided as per the TNM staging and risk factors present. Patients requiring palliative radiotherapy for brain metastasis, bone metastasis, and spinal cord compression are usually treated over 1-3 weeks. However, at our center during the current scenario, we are practicing mostly single fraction or 5 \# radiotherapy for such cases.

Throughout India COVID-19 is in peak phase now, with the present-day scenario which is horrifying with 18000-20000 cases per day with 350-400 deaths, however, in Jharkhand, the per day cases are in the range of 30-90 [1]. But among all these odd figures, we have a good recovery rate of $71 \%$ in Jharkhand while $58 \%$ of this virus in India [1]. We, Oncologists, know this is a tough time for all and additionally, this virus is going to stay for long in the world, till the successful launching of a vaccine against this virus. Till then we have to face this challenge with all wiseness and appropriate strategies in cancer patient care.

\section{Acknowledgements}

Authors acknowledge all authors contribution in the preparation of this manuscript.

\section{Disclosures}

The authors disclose that there is no financial support for this article and also, there is no conflict of interest among the authors.

\section{References}

1. www.mygov.in/covid-19.

2. www.covid19.who.int/?gclid.

3. Kursumovic E, Lennane S, Cook T. Deaths in healthcare workers due to COVID-19: the need for robust data and analysis. Anaesthesia. 202005 23;75(8):989-992. https:// doi.org/10.1111/anae.15116

4. Guan W, Liang W, Zhao Y, Liang H, Chen Z, Li Y, Liu X, Chen R, Tang C, Wang T, Ou C, Li L, Chen P, Sang L, Wang W, Li J, Li C, Ou L, Cheng B, Xiong S, Ni Z, Xiang J, Hu Y, Liu L, Shan H, Lei C, Peng Y, Wei L, Liu Y, Hu Y, Peng P, Wang J, Liu J, Chen Z, Li G, Zheng Z, Qiu S, Luo J, Ye
C, Zhu S, Cheng L, Ye F, Li S, Zheng J, Zhang N, Zhong $\mathrm{N}, \mathrm{He}$ J. Comorbidity and its impact on 1590 patients with COVID-19 in China: a nationwide analysis. European Respiratory Journal. 202003 26;55(5):2000547. https://doi. org/10.1183/13993003.00547-2020

5. https://www.mohfw.gov.in/pdf/LabTestingAdvisory.pdf..

6. Thomson DJ, Palma D, Guckenberger M, Balermpas P, Beitler JJ, Blanchard P, Brizel D, Budach W, Caudell J, Corry J, Corvo R, Evans M, Garden AS, Giralt J, Gregoire V, Harari PM, Harrington K, Hitchcock YJ, Johansen J, Kaanders J, Koyfman S, Langendijk J, Le Q, Lee N, Margalit D, Mierzwa M, Porceddu S, Soong YL, Sun Y, Thariat J, Waldron J, Yom SS. Practice Recommendations for Risk-Adapted Head and Neck Cancer Radiation Therapy During the COVID-19 Pandemic: An ASTRO-ESTRO Consensus Statement. International Journal of Radiation Oncology*Biology*Physics. 2020 07;107(4):618-627. https://doi.org/10.1016/j.ijrobp.2020.04.016

This work is licensed under a Creative Commons AttributionNon Commercial 4.0 International License. 